\title{
A New Era for Drug Trafficking: Drones
}

\author{
Zeynep Turkmen* and Merve Kuloglu \\ Institute of Forensic Sciences, Istanbul University, Turkey \\ *Corresponding author: Zeynep Turkmen, Institute of Forensic Sciences, Istanbul University, Turkey

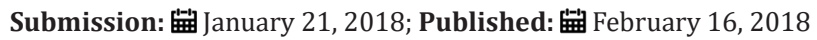

\begin{abstract}
In our contemporary World, drones (unmanned aerial vehicles-UAV) enter our daily life due to its increasing usage area. Looking at the history of drones, while they were used for military purposes at the beginning, nowadays they are adapting to a wide range of social activities from advertisements to extreme sport videos.

However, drones have been reported to be abused for illegal drug transfers along the country borders and within the countries. With this method, the most transported drug is methamphetamine, while the others are heroin, cannabis, and cocaine. Furthermore, the release of illegal drugs into prisons through the drones is a critical danger that our awareness must be raised.
\end{abstract}

In present study, cases and outbreaks of illegal substance transports via drones were examined through various search engines. In this respect, it is aimed to draw attention to such events and to contribute to take the necessary precautions at global scale.

Keywords: Drug trafficking with drones; Drones smuggling drugs; Drug transport; Unmanned aerial vehicles (UAV); Aerial security

\section{Introduction}

In our contemporary World, with the developing technology, drones enter our daily life due to its increasing usage area and wide price ranges. The word drone means "male bee" in English and describes shortly as unmanned aerial vehicles (UAV), appeared as a tool for surveillance in early 1900s Newcome [1] and Clarke [2]. Nowadays, market demand is increasing, because the use of drone is considered as more effective and lower cost than other transportation means such as airplanes.

Drones can be categorized as their types (fixed wing, multipropeller, etc.), degree of autonomy, size/weight and power source. These features can affect the payload capacity, cruising range and also maximum flight time. The technology used to fly a drone defines the drone's type and also a decisive factor for the shape and appearance. Another remarkable feature is; the difference in magnitude between drones. Their size can range from an insect size to the size of a commercial flight. Weights are another key influence and can range from a few grams to hundreds of kilograms (Clarke [2], Vergouw et al. [3]).

The most important feature that determines the carrying capacity of the drones in relation to the transport of illegal substances subject to this study is the type of energy source they use. Lots of energy sources like battery cells, solar batteries and conventional aircraft fuels can be used (Boucher [4]).

They are also classified according to an additional device attached to the body of the drones. In practice, almost any device can be fitted to the drone to serve various purposes, but the weight and dimensions of the loads are a major restraint. Drones are often equipped with cameras by their manufacturers. Moreover, other connection devices such as sensors can be added as well (Vergouw et al. [3]).

For a flight to take place, the drone needs a wireless connection with the person controlling it. There is also a connection needed with a camera or sensor that puts extra strain on the body. The frequency spectrum is required for these connections and this requirement depends on different factors such as device type and carrying capacity (Vergouw et al. [3]).

The aim of this study is while presenting every-day use of drones and its features contributing to the forensic science field, to emphasize the fact that their abuse for illegal substance transfer. The scope is to raise awareness about the prevention of crime and to give rise to thought what kind of security measures are needed in order to avoid such problems at an international level.

\section{Materials and Method}

Due to the limited number of articles and the lack of information on the subject, backward from January 2017, the literature has been searched by using the keywords "Drug trafficking with Drones”, “Drugs \& Drones", "Drone Regulations”, “Spy Drones”, via major bibliometric databases (Web of Science, Google Scholar, and Researchgate), as well as all web-based sites included judicial institution pages, newspapers and conference notifications through search engines such as Google and Bing in order to find cases involving illegal substance transfers and trades with drones. 


\section{General Application Areas}

Looking at the history of drones, it seems that they are used for military purposes at the beginning, and nowadays they are adapting to a wide range of social activities from commercials to extreme sports and travel promotional videos (Clarke [2]). In addition to this, the possibility of being used in the health field for emergency interventions, thanks to its rapid mobility, is a sign that its name will be heard frequently in the following days (Subbarao et al. [5], Mitka \& Mouroutsos [6]).

In the US and New Zealand distribution of ordered food products with drones has already begun (Pepitone [7]). However, it should be known that these activities are largely promotional purposes as they mostly reduce logistical costs. Although drones are often used in post and other cargo deliveries in practice, it is thought to be of great benefit in exploring new energy sources in remote areas as well (Mitka \& Mouroutsos [6]). The contribution of the use of drones to the scientific world for various observations and studies is another area that is growing rapidly. Drones can be very useful in collecting all kinds of research data, for instance, in meteorology, humidity, pressure, temperature, wind force and radiation data can be collected through drones (Clarke [2], Vergouw et al. [3], Mitka \& Mouroutsos [6]).

Furthermore, drones have a potential to provide new scientific data, especially related to the environment, atmosphere and climate, where it is difficult or expensive to reach until now (Mitka \& Mouroutsos [6]). Having a better and more detailed examining capacity compared to satellites has also made the use of drones in archeology widespread (Casana et al. [8], Euronews [9]). It can similarly be useful in mapping and tracking urbanization and traffic flows. On the other hand, in geological surveys, drones are very important in finding oil and gas resources (Dillow [10]).

To obtain this information, existing models can be developed by customizing them or hand-made drones can make by focusing on the need such that more accurate estimates can be obtained.

\section{Drones in Forensic Sciences}

It is indisputable fact that Mobile Security Systems Integration (MOBESE), fixed cameras and facial recognition systems have strengthened the hand of law enforcements in the fight against crime. In this regard, it is inevitable for drones equipped with mobile security cameras to serve this area more effectively.

Furthermore, it is believed that drones may contribute to search and rescue work in rough and hard-to-find places, as well as crime screening, crime scene reconstruction, and capturing the suspect (Subbarao et al. [5], Mitka \& Mouroutsos [6]).

Moreover, drones offer the opportunity to monitor and investigate without contaminating the scene and harming the physical evidences. This will provide rather healthy crime scene investigation, especially in outdoor and large-areas.

In addition to this, with the help of sensors with different features attached to the new generation drones, the area covered by the crime can be narrowed, also the time and effort spent in investigations can be shortened. To illustrate, with the aid of heat, chemical or biological sensors, detecting drug traffickers and their personal spaces can be easier because the particular sensor can facilitate investigations by taking the "smell" of chemical or biological compounds and microorganisms (Mitka \& Mouroutsos [6]).

Drones and other unmanned aerial vehicles have been used by the US government for years to secretly track the militant and terrorist mobility, to reach the victims of the hurricane, firefighting, to facilitate rescue, and at the same time to monitor illegal custom activities (Restas [11,12], Mitka \& Mouroutsos [6]). It has been one of the most common surveillance methods in recent years, particularly for identifying strong Mexican cartels and their American connections (Rawlins [13]). It is therefore not surprising that criminals also create awareness on this issue and adapt these similar methods to illegal use.

\section{Illegal Substance Trafficking with Drones}

Unfortunately one of the biggest problems of our modern world is the abuse of developing technology, which is also supported by the case reports below in detailed. The resulting misuses are already causing problems and affecting people's approach to the drones in the negative direction. The most up-to-date misuse is illegal substance trafficking with drones, which we have recently seen in various states of Mexico, Colombia and the United States.

Security officials in various countries have pointed out that illegal drug traffickers use hand-made drones for preliminary investigations on sites such as harbors or prisons to make observations and more advanced drones are used to transport illegal substances (Valencia \& Martinez [14]).

Experts claim that a drone weighing $45 \mathrm{~kg}$ can transport around $100 \mathrm{~kg}$ of cocaine in one go (Business Insider [15]). Especially in Mexico, with this method, cartels that are going to trade illegal substances across borders have largely overcome the problem of being captured their members at the expense of lowering their profits.

It is reported that among the illegal substances carried by this method, methamphetamine is in the first order, heroin is second, third is cannabis and cocaine is in the fourth place (Henry [16]). In the following, cases of illegal substance transfers using drones are presented.

\section{Reported News and Cases}

\section{Case 1}

In June 2015, Mexico's Tijuana region, DJI Spreading Wings 900 model carrying capacity of $8 \mathrm{~kg}$ crashed to the ground. It resulted in the seizure of $3 \mathrm{~kg}$ methamphetamine, which was banded to the body. Regarding this event, the regional authorities have indicated that there has been an increase in drug transport with the drones in recent times (Valencia \& Martinez [14]). 


\section{Case 2}

In the Oklahoma State of the United States, a drone was caught by prison authorities, attached to a line at the tip, crashed into one of the inner walls of the district prison. It has been determined that the packet connected with the line was carrying 2 knives, 1 mobile phone and battery, cigarette with $150 \mathrm{~g}$ cannabis, $23 \mathrm{~kg}$ methamphetamine and approximately gram heroin (Fieldstadt $\mathrm{E}$ [17]).

\section{Case 3}

It is reported that similar shipments were made in a high security prison in England as well. Drug and weapon shipments with drones, which first took place in a prison in 2015, demonstrate how vulnerable prisons are to these packages dropped from air, regardless of the level of safety, as stated also by the authorities (Milmo C [18]).

\section{Case 4}

Two people attempting to send marijuana, buprenorphine, tobacco, and pornography DVDs to a prison in Baltimore, Maryland, were caught before not even flying the drone (Swearingen J [19]).

\section{Case 5}

In August 2015, 66kg of tobacco, $30 \mathrm{~kg}$ of cannabis, and $3 \mathrm{~g}$ of heroin package was reported to have left by a high-flying drone in Mansfield, Ohio. The shipment was not realized until a fight began between an inmate for whom the shipment was intended to and other prisoners who wanted to take the package. The authorities had to use pepper gas to regain control over the fight (Swearingen J [19]).

\section{Case 6}

In Calexico, a small city near San Diego in August 2015, two people were caught trying to smuggle $13 \mathrm{~kg}$ of heroin using a drone at the border of California (Swearingen J [19]).

\section{Case 7}

Four people were arrested in Morgan, Georgia, in 2013, when the guards saw a drone wandering over the prison garden. They caught with a remote control, binoculars and some tobacco in their hands. According to officials, the binoculars found on the person can be used to follow up the shipment (Swearingen J [19]).

\section{Case 8}

One person was arrested while the other person escaped due to controlling a drone, which was crashed on the outside wall of a prison near Charleston city of South Carolina, carrying a mobile phone, cannabis, and tobacco. After the incident in July 2014, the prison official explained that the technology used by the criminals is gradually evolving and that there must be ways to fight it (Swearingen J [19]).

\section{Case 9}

January 22, 2015 in San Diego, California, a crashed drone was found on the ground. It is stated that the seized hand-made drone was carrying about $3 \mathrm{~kg}$ of crystalline methamphetamine (Kaufman S [20]).

\section{Case 10}

In 2014, a 28-year-old man in Melbourne Australia was arrested for attempting to infiltrate an unknown amount of illegal material into a prison with the help of a small drone (Anderson B [21]).

\section{Case 11}

A small drone flying near a prison wall was seen in Gatineau, Canada, in November 2013. However, the drone could not be found after the investigation, which had let to the idea that the drone could have been sent to discover the prison (Anderson B [21]).

\section{Legal Regulations and Precautions}

In addition to widespread use of drones in drug trafficking, nowadays, secret services, international agents and some curious people use drones for collecting, recording and tracking of secret information by violating other people's private lives (Finn \& Wright [22]). This issue raises many ethical concerns among societies in a global scale. The use of the drones in such a way that violating people's rights and freedoms has undoubtedly made it mandatory for governments to deal with the issue of drone in detail and to make legal arrangements on the subject. Countries like USA, Argentina, Australia, Brazil, France and England seem to regulate certain laws regarding the use of drone, while some countries are still focusing on the useful points of drones and closing their ears to other negative developments (Henry [16]). Some governments have already begun to develop new legislations on drones. Singapore, at the forefront of these countries, is currently working on a project based on Nanyang Technology University to develop landing and airfield control systems for drones (Nanyang Technological University [23]). In addition, NASA has reported that they have been developing a drone air traffic control system (Lozano [24]).

In Turkey, the Turkish Directorate General of Civil Aviation (SHGM) introduced a sanction to be applied on drones used in the Turkish airspace, officially launched on February 22, 2016. Accordingly, it is imperative that all UAVs between $500 \mathrm{~g}$ and $25 \mathrm{~kg}$ are used in the Turkish airspace; need to register with the web-based system (Nijim M \& Mantrawadi N [25]). It can be seen that, different countries work on different measures related to developing web based UAV registration systems and radar control units.

Nevertheless, there is still a need to work to improve the radar detection of drones in airspace globally, since the frequency spectrum does not end at the national borders, the use and supervision of international coordination is also necessary (Nijim \& Mantrawadi [18]).

\section{Discussion and Conclusion}

According to web-based research results that were made retrospectively starting from January 2017; the most commonly encountered illegal drugs transferred by drones are methamphetamine, cannabis and heroin respectively. Besides, guns, 
knives, money, fake passports and documents, cell phones, and porno DVDs were also found. This indicates that these smuggling acts bring other crimes such as document forgery, assault and battery together. Due to the drones' ability of airdropping packages to the prisons, it is considered that the behavior of prisoners may be affected by these shipments of illegal substance and weapons. In England, officials thought that fights' severity among prisoners and stuff has increased notably since drones often transport drugs and weapons (Milmo C [18]).

The most observed country in the reported news and cases of drug trafficking with drones is United States and it is followed by Mexico, which is not surprising considering the cartels and wellknown corruptions across the country (Rawlins [13]).

Considering the locations of the drones recovered, prisons and country borders are places where this danger is most active. However, the reported cases clearly indicate that there is a lack of awareness and measures regarding to this problem as in most of the cases, drones were only discovered because they had been hit to ground. Additionally, it is understood that in the case of drug transporting to prison by drones, if they have not been detected by an institutional operation yet, the conflict of interest between prisoners reveals the situation.

The reasons behind these hitting to ground patterns: the use of handmade drones with inadequate carrying capacity, poor coverage of the frequency spectrum, integration errors of hand-made devices and systematic mistakes of drone remote controllers could be main ones. Despite all of these possible errors, the multitude of unregistered hand-made drone use suggests that criminals intend to escape from the law and hand-made drones make difficult to be followed. Moreover, the authorities also mention the possibility that various attempts have been made to study the range and payload capacities of hand-made drones by sending them illegal substances attached in much less amounts than their carrying capacity.

In addition, illegal groups have largely overcome the problem of being captured at the expense of lowering their profits. Therefore, it will be inevitable for drones to become a method that can be accessed and preferred by almost every sector that deals with illegal drugs, from large cartels to small dealer groups in a short period of time [26-32].

As a conclusion, countries with geographical and geopolitical significance in illegal substance trafficking should be more aware of drug transports with drones. Likewise, it is suggested that the legislative countries need to be more cautious about unregistered hand-made drones and need more effective measures especially at the borders and in prisons. Taking measures without further development of this new shipment method, which is still being tried to improve, is very important in terms of prevention of crime.

\section{References}

1. Newcome, Laurance R (2004) Unmanned aviation: A brief history of unmanned aerial vehicles. virginia: American institute of aeronautics and astranautics, Inc.
2. Clarke R (2014) Understanding the drone epidemic. Computer Law \& Security Review 30(3): 230-246.

3. Vergouw B, Nagel H, Bondt G, Custers B (2016) Drone Technology: types, payloads, applications, frequency spectrum issues and future developments. In: Custers, Bart (Eds.) The Future of Drone Use, TMC Asser Press, Germany, pp. 21-45.

4. Boucher JR (1984) History of solar flight. Proceedings of the AIAA/SAE/ ASME $20^{\text {th }}$ Joint Propulsion Congress.

5. Subbarao I, Cooper GP Jr (2015) Drone-based telemedicine: A brave but necessary new world. J Am Osteopath Assoc 115(12): 700-701.

6. Mitka E, Mouroutsos S G (2017) Classification of Drones. American Journal of Engineering Research 6(7): 36-41.

7. Pepitone J (2013) Domino's tests drone pizza delivery. CNN.

8. Casana J, Kantner J, Wiewel A, Cothren J (2014) Archaeological aerial thermography: a case study at the chaco-era blue j community, New Mexico. Journal of Archaeological Science 45: 207-219.

9. Euronews (2013) Drone-assisted archeology.

10. Dillow C (2013) Norwegian geologists begin drone-guided quest for oil. Popsci.

11. Restas A (2012) Unmanned aircraft system applications: firefighting. introduction to unmanned systems: air, ground, see \& space. In: LeMieux J (Ed.), Technologies and Commercial Applications, LCCN 2012954516

12. Restas A (2015) Drone applications for supporting disaster management. World Journal of Engineering and Technology 3(3): 316321.

13. Rawlins A (2011) Mexico's drug war" Backgrounder. The Council on Foreign Relations.

14. Valencia N, Martinez M (2015) Drone carrying drugs crashes south of US border. CNN.

15. Christopher W (2016) Colombian traffickers have added drones to their smuggling arsenal. Business Insider.

16. Henry J (2015) High tech drones own the sky: the next wave in drug trafficking. Chicago Heights Patch.

17. Fieldstadt E (2015) Drone carrying package with drugs and blades found in oklahoma prison yard. NBC NEWS.

18. Milmo C (2015) Drones operated by criminal gangs used to deliver drugs mobile phones and potentially firearms to prisoners, admit senior officials. Crime.

19. Swearingen J (2015) 6 Drones turned drug mules-when UAVs turn to a life of crime. Popular Mechanics.

20. Kaufman S (2015) The 4 drones mexican drug lords should be using. Vocativ.

21. Anderson B (2014) How drones help smuggle drugs into prison. Motherboard.

22. Finn RL, Wright D (2012) Unmanned aircraft systems: Surveillance, ethics and privacy in civil applications. Computer Law \& Security Review 28(2): 184-194.

23. Nanyang Technology University (2017) Engineers develop air traffic control system for drones in Singaporean airspace.

24. Lozana S (2015) First steps toward drone traffic management. NASA Ames.

25. Birinci Bölüm (2016) İnsansız Hava Aracı Sistemleri Talimatı. SHGM.

26. Nijim M, Mantrawadi N (2016) Drone classification and identification system by phenome analysis using data mining techniques. IEEE Symposium. 
27. Cook J (2016) A vision of the future: Cargo drones could improve patients' access to surgery in low-income countries. British Journal of Surgery 103: 88-89.

28. McKelvey N, Diver C, Curran K (2015) Drones and Privacy. IJHCR 6(1): 44-57.

29. Sandvik KB, Lohne K (2014) The rise of the humanitarian drone: giving content to an emerging concept. Millennium 43(1): 145-164.

For possible submission use the below is the URL
30. Thompson G, Mazzetti M (2011) US drones fight mexican drug trade. New York Times.

31. Wall T, Monahan T (2011) Surveillance and violence from afar: The politics of drones and liminal security-scapes. Theoretical Criminology 15(3): 239-254

32. Wozniacka G (2013) Drones could revolutionize agriculture, farmers say. Huffington Post.

\section{Your subsequent submission with Crimson Publishers} will attain the below benefits

- High-level peer review and editorial services

- Freely accessible online immediately upon publication

- Authors retain the copyright to their work

- Licensing it under a Creative Commons license

- Visibility through different online platforms

- Global attainment for your research

- Article availability in different formats (Pdf, E-pub, Full Text)

- Endless customer service

- Reasonable Membership services

- Reprints availability upon request

- One step article tracking system 